\title{
Design of low sidelobe Microstrip antenna array
}

\author{
Gyapti Jain ${ }^{1}$, Rabindra Kumar ${ }^{2}$, Dr.Jayanta Ghosh ${ }^{3}$ \\ ${ }^{1}$ (Electronics and Communication, NIT Patna, India) \\ ${ }^{2}$ (Electronics and Communication, NIT Patna, India) \\ ${ }^{3}$ (Electronics and Communication, NIT Patna, India)
}

\begin{abstract}
A low side lobe level is obtained using Tschebyscheff amplitude tapering. To obtain amplitude tapering Wilkinson power divider is used. Two antenna structures are designed, first is conventional corporate feed array that operates at $5.5 \mathrm{GHz}$ with a side lobe level of $-12.7 \mathrm{~dB}$. The second structure is designed through appropriate Tschebyscheff distribution. It results in a decrease in $S L L$ to -15.4dB. The simulated results are presented and discussed.
\end{abstract}

Keywords: microstrip antenna array, sidelobe level, Tschebyscheff distribution, Wilkinson power divider

\section{Introduction}

Nowadays microstrip antenna arrays are used widely in the satellites, aircraft and other such applications where low- profile, light weight are main considerations. Antenna parameters such as sidelobe level (SLL) [1] and bandwidth, play a very crucial role in many radar systems. The sidelobe levels between $-5 \mathrm{~dB}$ and $-20 \mathrm{~dB}$ is referred as low sidelobe levels, and levels below $-20 \mathrm{~dB}$ are referred as ultralow side lobe levels[2]. Printed antenna arrays with SLL lower than $-25 \mathrm{~dB}$ are difficult to realize mainly due to: mutual coupling between radiating elements, surface wave effect, parasitic radiation from a feeding network, and tolerances in fabrication [1]. In the present work, a 4 element microstrip antenna array is designed using Tschebyscheff amplitude distribution[3] producing sidelobe level of $-15.4 \mathrm{~dB}$.

\section{Antenna Array Design}

The process starts with the designing of an inset fed rectangular patch antenna on a glass epoxy substrate having relative permittivity $\varepsilon_{r}=4.36$ and thickness of $1.6 \mathrm{~mm}$. The array is designed by arranging these four microstrip line feed patch antennas in linear configuration. The array is fed by corporate feed network. The matching technique used is quarter wave transformer impedance matching. The inter element spacing is an important factor in design of antenna array, so it has been varied and the effect of this variation on radiation pattern is observed.The variation of spacing changes the sidelobe level and beamwidth. The optimal results are obtained at a distance of $0.75 \lambda$ o. The conventional 4 element microstrip antenna array is shown in fig. 1.

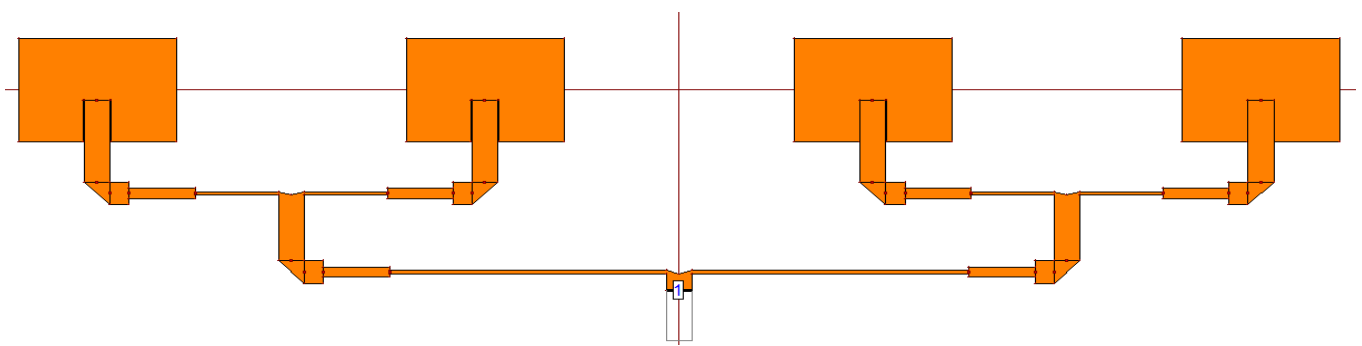

Figure 1. Conventional 4 - Element Microstrip Antenna Array

Fig. 2 shows the modified antenna array to get low sidelobe level. As can be observed this new design includes Wilkinson power divider[4]. The unequal Wilkinson power divider is responsible for the creation of the required tapered amplitude distribution. This power divider has a split ratio of 2:1. The array is designed for an appropriate Tschebyscheff distribution of $-16 \mathrm{~dB}$ taking into account the implementation restrictions of high impedance lines needed in the design of unequal Wilkinson power dividers. The normalized amplitude of each antenna element is shown in Table 1. 


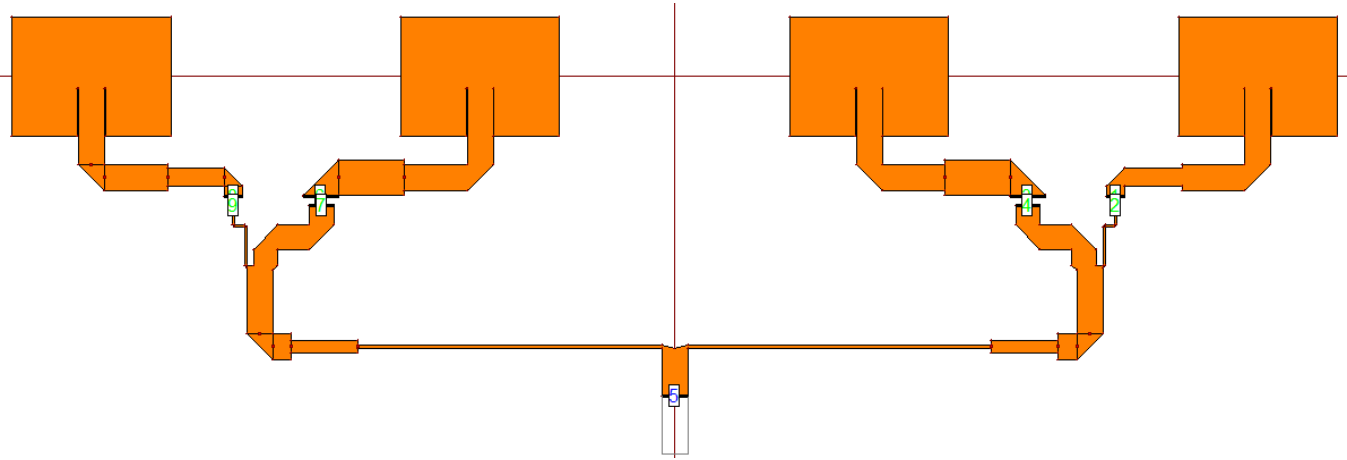

Figure. 2 Modified Antenna Array

Table 1. Normalized Amplitude Distribution

\begin{tabular}{|c|c|c|c|c|}
\hline $1 \times 4$ Array Amplitude & \multicolumn{4}{|c|}{ Element Number } \\
\cline { 2 - 5 } Distributions & 1 & 2 & 3 & 4 \\
\hline Normalized Amplitude & 0.707 & 1 & 1 & 0.707 \\
\hline
\end{tabular}

\subsection{Theoretical analysis of Rectangular patch}

The parameters of rectangular microstrip antenna such as width, effective dielectric constant, effective length, length extension and acutal length are calculated using the given equations [5] :

$$
\begin{aligned}
& \mathrm{w}=\frac{\mathrm{c}}{2 f_{0} \sqrt{\left(1+\varepsilon_{r}\right) / 2}} \\
& \varepsilon_{\text {reff }}=\frac{\varepsilon_{r}+1}{2}+\frac{\varepsilon_{r}-1}{2 \sqrt{1+\frac{12 \mathrm{~h}}{w}}} \\
& l_{\text {eff }}=\frac{\mathrm{c}}{2 f_{0} \sqrt{\varepsilon_{\text {reff }}}} \\
& \Delta l=0.412 \mathrm{~h} \frac{\left(\varepsilon_{\text {reff }}+0.3\right) \cdot\left(\frac{w}{h}+0.264\right)}{\left(\varepsilon_{\text {reff }}-0.258\right) \cdot\left(\frac{w}{h}+0.8\right)} \\
& l=l_{\text {eff }}-2 \Delta l
\end{aligned}
$$

In which, $l=$ length of the rectangular patch

$\mathrm{w}=$ width of the rectangular patch

$\mathrm{h}=$ thickness of the substrate material

$\mathrm{f}_{0}=$ resonant frequency

The width of microstrip transmission line $\left(W_{f}\right)$ is calculated using equation (6) :

$$
Z c=\left\{\begin{array}{cl}
\frac{60}{\sqrt{\varepsilon_{\text {reff }}} \ln \left[\frac{8 h}{W_{f}}+\frac{W_{f}}{4 h}\right],} & \frac{W_{f}}{h} \leq 1 \\
\frac{120 \pi}{\sqrt{\varepsilon_{\text {ref } f}}\left[\frac{W_{f}}{h}+1.393+0.667 \ln \left[\frac{W_{f}}{h}+1.444\right]\right]} & , \quad \frac{W_{f}}{h}>1
\end{array}\right.
$$

\subsection{Dimensions of Antennas}

The dimension of antennas e.g.length, width, dielectric constant, height, resonant frequency etc. has been calculated using above formulas which has been tabulated below.

Table 2. Antenna Dimensions

\begin{tabular}{|c|c|}
\hline Parameters & Values \\
\hline Resonant frequency, $f_{o}$ & $5.5 \mathrm{GHz}$ \\
\hline Dielectric constant, $\varepsilon_{r}$ & 4.36 \\
\hline Substrate thickness, $\mathrm{h}$ & $1.6 \mathrm{~mm}$ \\
\hline Length of patch, $\mathrm{L}$ & $12.5 \mathrm{~mm}$ \\
\hline Width of patch, $\mathrm{W}$ & $16.7 \mathrm{~mm}$ \\
\hline Width of $50 \Omega$ transmission line, $W_{f}$ & $2.718 \mathrm{~mm}$ \\
\hline Inset depth, $y_{o}$ & $5 \mathrm{~mm}$ \\
\hline Notch width , g & $0.091 \mathrm{~mm}$ \\
\hline
\end{tabular}




\subsection{Return Loss Plot}

\section{RESULT AND DISCUSSION}

The $S_{11}$ (input reflection coefficient) plot for the given patch antenna array is drawn by the simulation using IE3D software. The s11 plot for the conventional antenna array and modified array is shown in fig. 3(a) and 3(b) respectively. The conventional array is giving maximum return loss of $-26 \mathrm{~dB}$ at $5.5 \mathrm{GHz}$ and modified array is giving a return loss of $-21.45 \mathrm{~dB}$.

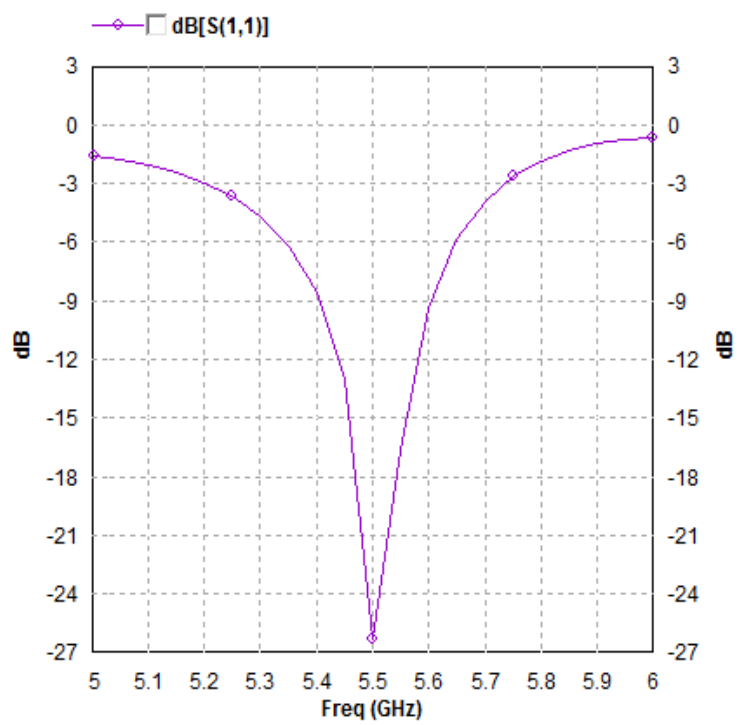

(a)

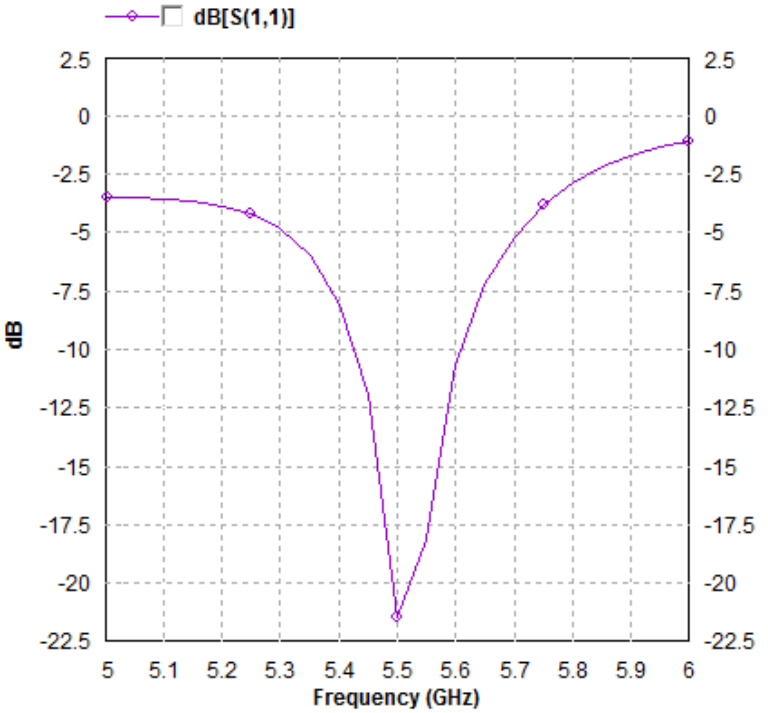

(b)

Figure 3(a) Return loss plot for conventional antenna array (b) Return loss plot for modified antenna array

\subsection{Radiation Pattern}

The radiation pattern of conventional microstrip antenna array is shown in fig 4(a). it gives the maximum gain of $10.1673 \mathrm{~dB}$ in broadside direction and side lobe level of $-12.7 \mathrm{~dB}$. The modified array gives a side lobe level of $-15.4 \mathrm{~dB}$ with maximum gain of $10.57522 \mathrm{~dB}$ in broadside direction as shown in fig. 4(b). The half power beamwidth of conventional array and modified array is $16^{\circ}$ and $20.1^{\circ}$ respectively. Both array radiates in broadside direction with no back lobes. 


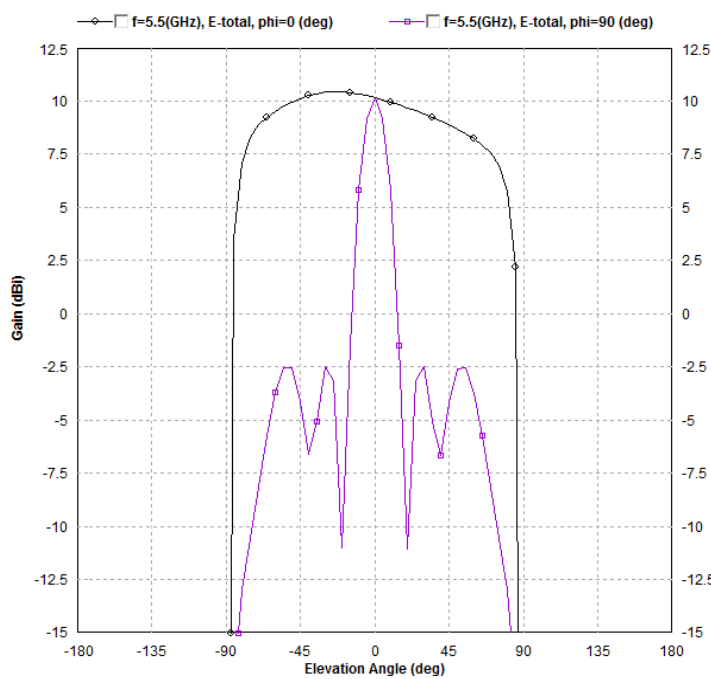

(a)

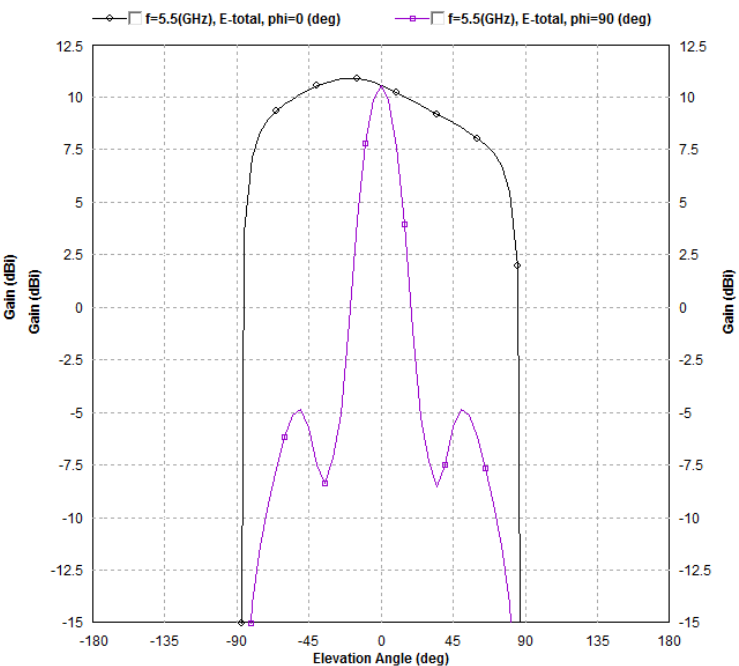

(b)

Figure 4(a) Radiation Pattern for conventional antenna array (b) Radiation Pattern for modified antenna array

\section{Conclusion}

Two arrays are designed at $5.5 \mathrm{GHz}$. Tschebyscheff amplitude tapering is used to decrease the side lobe level. The results show that side lobe level is reduced by $-2.7 \mathrm{~dB}$. The simulated result shows that as side lobe level decreases beam width increases. The side lobe level can be further reduced if a substrate having low dielectric constant is used.The antenna shall be suitable for wireless communication system applications in $\mathrm{C}$ band $(4-8 \mathrm{GHz})$.

\section{References}

[1]. A. Nesic, Z. Micic, S. Jovanovic, and I. Randonvic, "Millimeter wave printed antenna array with high side lobe suppression," in Proc. IEEE AP-S Int. Symp., 2006, pp. 3051-3054.

[2]. D. M. Pozar and B. Kaufman, "Design considerations for low sidelobe microstrip arrays," IEEE Trans. Antennas Propag., vol. 38, no. 8, pp. 1176-1185, Aug. 1990.

[3]. C.L.Dolph, "A current distribution for broadside arrays which optimizes the relationship between beamwidth and side lobe level," Proc.IRE and Wavesand Electrons, June 1946, pp. 335-348

[4]. David M. Pozar, Microwave Engineering, $3^{\text {rd }}$ ed.(India, John Wiley, Reprint 2007)

[5]. Constantine A. Balanis,Antenna theory, $3^{\text {rd }}$ ed.(India, John Wiley, Reprint 2010) 